\title{
Caracterización molecular de Heliconia sp. Utilizando la técnica RAPD.
}

\section{Molecular characterization of Heliconia sp. using RAPD technique.}

\author{
Freddy Gutierrez ${ }^{1}$, Roberson Ramirez ${ }^{1}$, Pedro Adrianzén ${ }^{1,2}$, Marianela Cobos ${ }^{1}$, Sergio Pinedo ${ }^{3}$, Sixto Imán ${ }^{3}$ \\ Juan Castro ${ }^{1,2}$ \\ 1 Centro de Investigaciones de Recursos Naturales de la Amazonia (CIRNA), 496S. \\ 2 Universidad Nacional de la Amazonia Peruana-UNAP. Apartado postal 496S Facultad de Ciencias \\ Biológicas. \\ 3 Instituto Nacional de Innovación Agraria (INIA), C.P. 609.
}

\section{RESUMEN}

Este trabajo se realizó entre los meses de Julio a Setiembre del 2010, con el objetivo de caracterizar molecularmente a la especie Heliconia sp. Utilizando el marcador molecular RAPD. Para esto, se realizó la purificación del ADN genómico de la especie en estudio obteniéndose buenos resultados en cuanto a la calidad y la cantidad del ADN purificado, el cual fue verificado con los métodos electroforético y espectrofotométrico, la cantidad de ADN obtenido en promedio fue de $92.8 \mathrm{ng} / \mu \mathrm{l}$, asimismo el ratio de calidad promedio fue de 2.2. Para la amplificación de los productos de la PCR se empleó el iniciador MT3R, obteniéndose mucho polimorfismo. Los productos de la PCR tuvieron tamaños de 750 pb hasta 2050 pb. En cuanto a la caracterización molecular, se realizó un dendograma (UPGMA) utilizando el programa estadístico NTSIS versión 2.0. Asimismo se obtuvo la formación de 2 grupos (clusters) y 2 fugas donde se observó la aparición de "aparentes duplicados" en algunos de ellos, es decir, que comparten el mismo patrón genético con un $100 \%$ de similitud. Además el valor de la heterocigosidad esperada fue de 0.14 , valor relativamente bajo, posiblemente al tipo de reproducción que posee este género, el cual es la autogamica.

Descriptores: ADN genómico, Heliconia sp, electroforético, espectrofotométrico.

\section{ABSTRACT}

This work was carried out between the months of July to September 2010 with the objective of molecular characterization of the species heliconia sp using the RAPD molecular marker. For this, we performed the purification of genomic DNA, of the species under study with good results in terms of quality and quantity of purified DNA, which was verified by electrophoretic and spectrophometric methods, the amount of DNA obtained was on average $92.8 \mathrm{ng} / \mu \mathrm{l}$, also the ratio of average quality was 2.2. For amplification of PCR products was used MT3R initiator, obtaining much polymorphism. PCR products had sizes of 750 bp to 2050 bp. as for the molecular characterization, we performed a dendrogram (UPGMA) using the statiscal sofwar version 2.0 NTSIS. It also obtained the formation of 2 groups (clusters) and 2 leaks where we the appearance of "apparent duplicates" in some of them, ie they share the same genetic patern with $100 \%$ similarity. Also, the value of expected heterozygosity was 0.14 , relatively low value, possibly the type of reproduction that has this kind, which is the autogamous.

Keywords: genomic DNA, Heliconia sp, electrophoretic, spectrophometric.

\section{INTRODUCCIÓN}

La familia Heliconiaceae contiene un solo género, Heliconia con aproximadamente 180 especies del origen de Neotropicales. Este género fue asignado antes a la familia Musaceae, pero forma hoy a su propia familia, en el orden Zingiberales [1] La combinación de flores invertidas, de un solo estaminodio y de frutas de las drupas es una característica exclusiva de Heliconia sp. Las Heliconias son plantas exóticas, no solo por la belleza sino por el hecho de lo poco que se sabe acerca de ellas. Esta especie se diferencia de las otras por su porte imponente, su rápido crecimiento y la gran durabilidad de su inflorescencia, que a su vez cortada puede durar una semana sin marchitarse [2]. 
ECIPERÚ

Hasta el momento, las investigaciones que se han registrado para este grupo de especies en la Amazonía Peruana, se limitan principalmente a la presentación de inventarios y descripciones morfológicas. Ante ello, surge la necesidad de realizar estudios a nivel molecular por medio de los marcadores moleculares como por ejemplo, la utilización del marcador RAPD (Polimorfismo de ADN amplificado arbitrariamente), que permite la detección del polimorfismo del ADN, distribuido en el genoma del organismo analizado, asimismo esta técnica, es una de las herramientas que ofrece la posibilidad de realizar un análisis genético detallado [3] facilitando así el estudio y el conocimiento de esta especie. Además es importante la caracterización molecular a esta especie porque nos permitirá realizar posteriores investigaciones relacionadas a este género, como aislamiento de genes de interés, estudios de variabilidad genética, estudios filogenéticos, caracterización de genotipos, etc. $Y$ estos estudios permitirán establecer las estrategias necesarias para el manejo y la conservación de esta especie.

\section{EXPERIMENTAL}

\section{Área de Estudio}

Se realizó en el Laboratorio de Biotecnología del Centro de Investigaciones de Recursos Naturales de la Amazonía (CIRNA) de la Universidad Nacional de la Amazonía Peruana; situada en el AA.HH. Nuevo San Lorenzo. Psje. Los paujiles S/N.

\section{Zona de muestreo y conservación de muestras.}

Se colectaron hojas jóvenes en buen estado, de un total de 26 individuos diferentes de la Estación Experimental Agraria "San Roque" Iquitos, Campo Experimental "El Dorado", ubicado en el Km 25 de la carretera Iquitos-Nauta, a 18M 0675950 UTM 9562758. Las muestras fueron colocadas individualmente en bolsas plásticas con sus respectivos códigos y puestas en un termo para su transporte inmediato al laboratorio, donde se procedió a lavarlas y fueron conservadas a $4{ }^{\circ} \mathrm{C}$, para su posterior análisis.

\section{Purificación del ADN genómico.}

Se utilizó el protocolo propuesto por [4] con algunas modificaciones, como la adición de $700 \mu l$ de buffer de extracción luego de la trituración de la muestra y homogenizando por 5 minutos, la conservación con isopropanol a $-20^{\circ} \mathrm{C}$ por un período de 24 horas y la centrifugación final a $13000 \mathrm{rpm}$ por 5 minutos. Los demás pasos corresponden a las citadas por el autor.

\section{Determinación de la calidad de ADN.}

Se preparó gel de agarosa al $2 \%$, teñido con bromuro de etidio $(1 \mathrm{mg} / \mathrm{ml})$, dejando reposar por 20 minutos para su gelidificación. Luego se sembró 10 $\mu \mathrm{l}$ de muestra y se corrió con Buffer TAE 1X (Tris pH 8.0, ácido bórico, EDTA) por 45 minutos a 85 voltios.

\section{Determinación de la cantidad de ADN.}

Se realizó utilizando un espectrofotómetro (GENESYS G). La absorción se midió en longitudes de onda de $260 \mathrm{~nm}$ y $280 \mathrm{~nm}$. Para ello, se empleó Buffer TE (Tris pH 8.0; EDTA) $1000 \mu \mathrm{l}$, como solución blanco y para la cuantificación del ADN, la dilución de 1/20 utilizando el buffer TE. Los resultados de calidad y cantidad fueron obtenidos con las siguientes fórmulas [5].

Calidad del ADN= Abs.260/Abs. 280

\begin{tabular}{|c|}
\hline Cantidad de ADN (ng/ul) \\
(Absorbancia)(Factor de Dilución)
\end{tabular}

\section{Amplificación del ADN genómico utilizando el marcador RAPD.}

Se realizó la PCR, la cual consistió en preparar una solución madre con un volumen total de $19 \mu \mathrm{l}$. Para la reacción, se empleó $\mathrm{H}_{2} \mathrm{O}$ ultrapura, Buffer 10X, $\mathrm{MgCl}_{2} 25 \mathrm{Mm}$, DNTPs $10 \mathrm{Mm}$, iniciador $5 \mu \mathrm{M}$, Taq DNA polimerasa $5 \mathrm{U} / \mu \mathrm{l}$ y ADN $1 \mu \mathrm{l}$. Las reacciones de amplificación se realizaron en un termociclador (Eppendorf) con las siguientes condiciones: 1 ciclo de $94^{\circ} \mathrm{C}$ por 4 minutos, 40 ciclos de $94^{\circ} \mathrm{C}$ por 30 segundos, $36^{\circ} \mathrm{C}$ por 30 segundos, $72^{\circ} \mathrm{C}$ por 30 segundos, extensión final a $75^{\circ} \mathrm{C}$ por 5 minutos y $4^{\circ} \mathrm{C}$ por tiempo indefinido.

\section{Preparación del Gel de Poliacrilamida.}

Se armó el molde y la mezcla de los siguientes reactivos: acrilamida bisacrilamida al $30 \%$, Buffer 5 $X$, Persulfato de amonio $0.3 \%$. Temed y $\mathrm{H}_{2} \mathrm{O}$ ultrapura. Se sembró $15 \mu \mathrm{l}$ de producto de PCR en cada uno de los pocillos. Utilizando un marcador de 100 pares de bases (pb) (PROMEGA). El tiempo de la corrida electroforética fue de 5 horas a 85 voltios. Los geles fueron teñidos utilizando la tinción argéntica [6]. 


\section{Análisis estadístico.}

Se utilizó el programa estadístico NTSYS versión 2.0, para elaborar un dendrograma, empleando el método UPGMA. Para esto se diseñó una matriz de doble entrada en el programa Microsoft Excel 2010, para registrar los datos binarios (presencia y ausencia de bandas). Además el cálculo promedio esperada se realizó en base a las formulas establecida para la heterocigocidad [7].

\section{RESULTADOS Y DISCUSIÓN}

\section{Calidad del ADN}

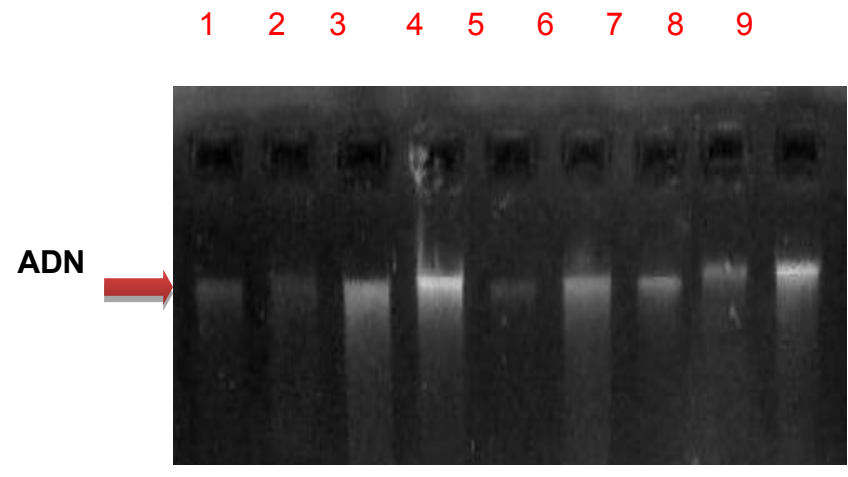

Figura 01: ADN genómico de Heliconia sp. Purificado según Ghislain et al.(1997)

En la figura 01 se evidencia las bandas de ADN de calidad aceptable, debido a que no se observa degradación, contaminantes como polisacáridos, polifenoles, etc. Además es muy notoria la cantidad debido a la intensidad de las bandas.

\section{Cantidad de ADN}

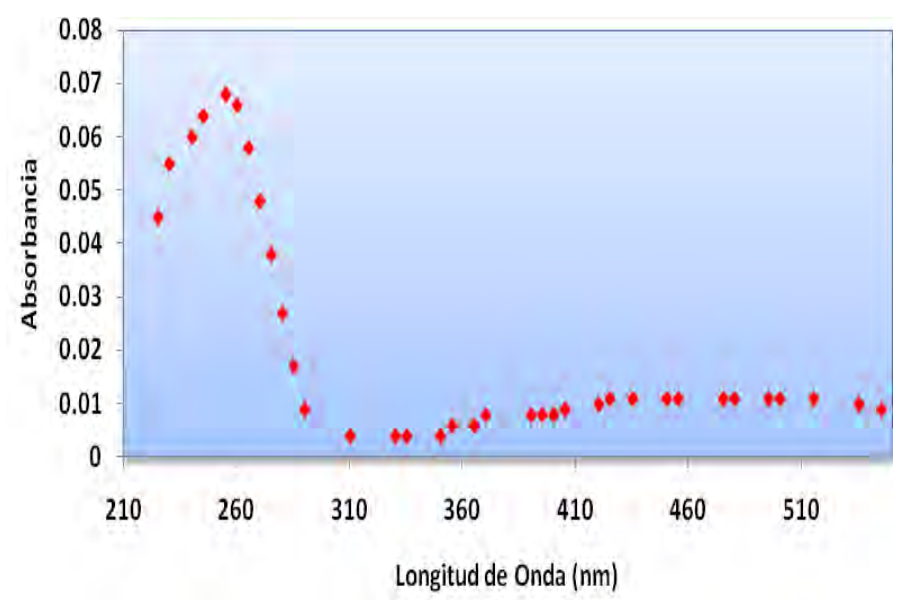

Figura 02: Absorbancia del ADN genómico de Heliconia sp. a $260 \mathrm{~nm}$

Al hacer un barrido espectrofotométrico de $200 \mathrm{~nm}$ a $510 \mathrm{~nm}$ de longitud de onda, es evidente la presencia de ADN genómico con la formación de una curva a $260 \mathrm{~nm}$. Con este método se obtuvo en promedio $92.8 \mathrm{ng} / \mu \mathrm{l}$ de concentración de ADN genómico y un ratio de calidad de 2.2 ideal, utilizando $70 \mathrm{mg}$ de hoja lo que demuestra la utilidad del protocolo de [4].

\section{Amplificación del ADN genómico}

Para la amplificación del ADN con el marcador molecular RAPD, utilizando el primer MT3R se obtuvo mucho polimorfismo. Los productos variaron de 750 a 2050 pb. Sin embargo [9], utilizó 10 primers obteniendo polimorfismo de bandas que variaban desde 400 a 2072 pb, patrones de bandas similares obtenidos en este trabajo. Los cebadores utilizados generaron de 2 a 5 bandas de ADN, siendo evidente el polimorfismo entre los genotipos. [3], mencionan que si se hubiera utilizado más iniciadores aumentaría la cantidad de polimorfismo, de esta forma se esperaría un incremento en el número de bandas, sin embargo no se reconocería que iniciador genera tales bandas de ADN.

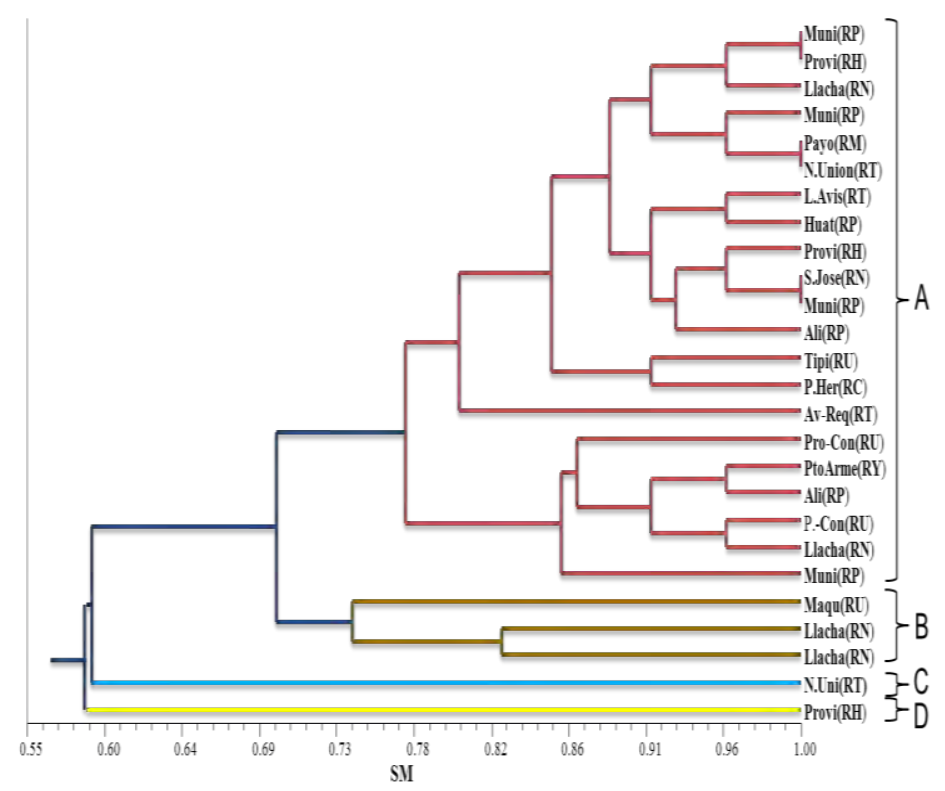

Figura 03: Dendrograma generado por el Método UPGMA

El dendrograma muestra a una similitud del $74 \%$, la formación de 2 grupos (clusters) y 2 fugas, asimismo se observa aparentes duplicados que comparten los mismos patrones genéticos, lo cual posiblemente nos indica la existencia de una baja variabilidad genética, también se observa que algunas muestras no están agrupadas, esto podría deberse a que se utilizó un solo primer. Además el índice de similaridad fue de 0.77 y una heterogocidad promedio de 0.14 , lo que indica una población homocigótica alta y por lo tanto se presume que existe una variabilidad genética baja. 


\section{CONCLUSIONES}

Se obtuvo ADN genómico de Heliconia sp. De buena calidad y cantidad con valores de $92.8 \mathrm{ng} / \mu \mathrm{l}$ de ADN y un ratio promedio de calidad de 2.2.

El cebador MT3R fue muy informativo debido a que los productos generados fueron muy polimórficos. $Y$ finalmente el valor de la heterocigocidad promedio esperada fue de 0.14 , lo que indica un bajo grado de variabilidad genética que existe entre la especies Heliconia sp. lo cual se debería al tipo de reproducción que presenta esta especie.

\section{AGRADECIMIENTOS}

Al proyecto "Aplicación de herramientas biotecnológicas para la clonación y obtención de líneas celulares de alto rendimiento de vitamina $C$ de Myrciaria dubia (HBK) Mc Vaugh "camu camu" por el financiamiento para la realización de este trabajo de investigación.

\section{REFERENCIAS}

[1] L. Marouelli, P. Inglis, M Ferreyra y G. Buso. 2010. Genetic relationships among Heliconia (Heliconiaceae) species based on RAPD markers. Pág. 1-11

[2] Agro tropical.2002. Heliconia stricta Huber. 2007. [Online] URL:

http://www.siac.net.co/sib/catalogoespecies/e specie.do

[3] D. Grattapaglia, M. Ferreira. Introducción a uso de Marcadores Moleculares en el análisis genético (1998) 1ra Edición Brasilia; Embrapa - Cernargen, Pág. 220.
[4] M. Ghislain, F. Rodriguez, F. Villalon, J Nuñez, R. Waugt y M. Bonierbale, 2000. Establishment of microsatellite assays for potato genetic identification. Centro International de la Papa (CIP). Programa Rep. Pág. $167-174$.

[5] R. De Jesus, N. Moreno y J. Martínez. 2005. Ensayo de dos métodos de extracción de ADN de ratón para ser usado en el control genético de ratones consanguíneos mediante la reacción en cadena de la polimerasa (PCR). Revista Científica, FCV-LUZ. V. 15, No 2, Pág. 134-140.

[6] J. Bassam \& M. Gresshoff 2007. Silver staining DNA in polyacrylamide gels, Nature protocols; Vol 2.

[7] Nei, Masatoshi (1975), molecular population genetic and evolution university of Texas at Houston. Pag. 166-169.

[8] H. Jimenez, W. Ramos, V. Loges, L. Vilela y Almeida H.2007. Caracterização molecular da coleção de germoplasma de Helicônias da Ufrpe. Pag. 1-3.

[9] J. Doyle and J. Doyle, JL 1987. A rapid DNA isolation procedure from small quantities of fresh leaf tissue. Phytochem. Bull. 19: 11-15

E-mail: biogutir_20@hotmail.com 